journal, Molecular Physics (1, No. 1; January 1958. Pp. 98. Published quarterly. Annual subscription : 95s. ; 13.30 dollars. Single issues : 25s.; 3.50 dollars. London: Taylor and Francis, Ltd., 1958), state in their brief editorial to the first number that the subject of molecular physics occupies a key position in modern science and that the frontier between physics and chemistry is disappearing as the methods of physics are brought to bear on the problems of chemistry. Probably not all chemists and physicists would agree with this rather bold statement; nevertheless they would agree that the introduction of a periodical devoted solely to contributions on the structure and physical properties of molecules is timely. Papers on molecular structure and dynamics, the electric and magnetic properties of molecules, and the processes of molecular excitation, ionization and dissociation, and the equilibrium transport and relaxation properties of molecular assemblies, will be particularly welcome, in addition to research notes. The first number containg ten articles and one research note. These deal with such subjects as nuclear magnetic resonance in substituted ethanes; dipole moments of azines ; critical opalescence in solid solutions; and six papers are devoted to theoretical problems, mainly of a mathematical nature, in quantum and statistical mechanics. One paper is in German, but all have abstracts in English, French and German. The format is similar to, and of the high standard associated with, other such scientific journals as the Philosophical Magazine published by Taylor and Francis, Ltd.

\section{Science and Education}

AN important statement on policy has been issued by the Committee of the Science Masters' Association (pp. 12. London: John Murray (Publishers), Ltd., 1957). Recognizing that science must be taught as a major human activity and as a cultural study of supreme importance because of its effects on human life and thought, the Committee suggests that the aims of science teaching should be three-fold : to lead pupils to observe, and to solve problems by controlled experiments, to draw conclusions from observations, and to appreciate the systematic laws and principles of science; to give knowledge and understending of the origins and development of science, of the achievements of scientific pioneers and of the implications, now and in the future, of modern scientific and technological developments; and for science specialists, to provide a suitable preparation for further scientific or technological education. The Committee recommends that all pupils should devote the same time to science subjects up to the end of the fifth-form year; that all sixth-form pupils should follow a cultural course in science and that subject-specialization should be retained in sixth forms and that science syllabuses at Advanced Level should be reduced in factual content. The recommendations raise many problems of syllabuses, of teaching methods, of suitable training for science teachers, and of examinations which will be examined in a future report.

\section{Clouds on Filmstrip}

Two filmstrips entitled "Clouds", accompanied by a 20-page booklet of lecture notes by $F$. H. Ludlam and Dr. R. S. Scorer of the Imperial College of Science and Technology, London, have been produced by Diana Wyllie, Ltd. (18 Pont Street, London,
S.W.1), in co-operation with the National Committee for Visual Aids in Education. In recent years much has been learned about the motions of the air and properties of the water droplets and ice crystals which compose the clouds, the growth and decay of which can be used to exemplify many branches of physics. The filmstrips, which are in colour, and made in many cases from photographs of great beauty, are chosen principally to illustrate the process of development of various types of cloud rather than their classification. The colour suffers slightly in the reproduction process, which, however, also tends to increase the contrast between cloud and sky, with advantage. The filmstrips, which deal respectively with haze (in relation to condensation nuclei), convection clouds and ice clouds (24 frames) and with layer, wave and billow clouds, with three explanatory diagrams (25 frames), are intended chiefly for use in schools and universities.

\section{Nucleonic Thickness Gauge}

BaLdwin Instrument Co., Lmp., Dartford, Kent, has published details of a new nucleonic thickness gauge for use in the cold-rolling of copper, brass or steel strip. The instrument can be used for thicknesses of steel up to $0.40 \mathrm{in}$., which is claimed to be about twice the upper limit for the nomal $\beta$-ray gauge. This increased range is obtained by using bremsstrahlung emitted when $\beta$-rays from strontium-90 impinge on a metal target. The intensity of the radiation after passing through the strip, which is related to strip thickness, is messured by the intensity of the scintillations produced in a sodium iodide crystal. The instrument would appear to be well suited to automatic gauge control, for which it feeds a bridge circuit that indicates the deviation of thickness from any desired value. When this deviation reaches a predetermined level, the screw-down mechanism of the mill is brought into operation. The intervals during which no strip is passing through the mill are utilized for automatic standardization.

\section{Bibliography of the Mysidacea}

A Usteve "Bibliography of the Order Mysidacea", which is carried up to the ond of 1955 , has recently been prepared by Joan Gordan (Bull. Amer. Mus. Nat. Hist., 112, $279 ; 1957)$. It is divided into three sections; the first, containing about 1,180 entries going back to O. F. Muller (1776), is a list of references arranged alphabetically. The second part is a list of the recorded species arranged in alphabetical order in their genera, which again are arranged alphabetic ally and grouped under five families. Under each species are listed the relevant page references in order of their date of publication. This arrangement makes it very easy to refer to the literature of any species for it includes the synonymy by cross-reference. The author points out that the work is not intended as a contribution to the systematics or taxonomy of the order and accepts the works of W. M., and W. M. and O. S. Tattersall (both of 1951) for these purposes. The third part arranges the literature under ten arbitrary but acceptable headings. That for distribution is subdivided into "Fresh and Brackish Water" and "Oceanic", and then each category is further divided into geographical regions. The printing and format are of the usual excellence of the Bulletin and the author is to be congratulated on a commendable contribution that will save future workers on the order a great deal of time. 